International Lending with Moral Hazard and Risk of Repudiation

Author(s): Andrew Atkeson

Source: Econometrica, Vol. 59, No. 4 (Jul., 1991), pp. 1069-1089

Published by: The Econometric Society

Stable URL: http://www.jstor.org/stable/2938174

Accessed: 08/12/2010 01:54

Your use of the JSTOR archive indicates your acceptance of JSTOR's Terms and Conditions of Use, available at http://www.jstor.org/page/info/about/policies/terms.jsp. JSTOR's Terms and Conditions of Use provides, in part, that unless you have obtained prior permission, you may not download an entire issue of a journal or multiple copies of articles, and you may use content in the JSTOR archive only for your personal, non-commercial use.

Please contact the publisher regarding any further use of this work. Publisher contact information may be obtained at http://www.jstor.org/action/showPublisher?publisherCode=econosoc.

Each copy of any part of a JSTOR transmission must contain the same copyright notice that appears on the screen or printed page of such transmission.

JSTOR is a not-for-profit service that helps scholars, researchers, and students discover, use, and build upon a wide range of content in a trusted digital archive. We use information technology and tools to increase productivity and facilitate new forms of scholarship. For more information about JSTOR, please contact support@jstor.org. 


\title{
INTERNATIONAL LENDING WITH MORAL HAZARD AND RISK OF REPUDIATION
}

\author{
By Andrew AtKeson ${ }^{1}$
}

\begin{abstract}
In this paper, I examine the constrained optimal pattern of capital flows between a lender and a borrower in an environment in which there are two impediments to forming contracts. The first impediment to contracting arises from the assumption that lenders cannot observe whether borrowers invest or consume borrowed funds. This assumption leads to a moral hazard problem in investment. The second impediment arises from the assumption that the borrower, as a sovereign nation, may choose to repudiate his debts. The optimal contract is shown to specify that the borrowing country experience a capital outflow when the worst realizations of national output occur. This seemingly perverse capital outflow forms a necessary part of the optimal solution to the moral hazard problem in investment.
\end{abstract}

KEYwORDS: Sovereign lending, risk of repudiation, moral hazard, dynamic games.

\section{INTRODUCTION}

THE HISTORY OF INTERNATIONAL LENDING over the last one hundred and fifty years is marked with numerous episodes in which an indebted country has been denied new loans and has been asked to repay its outstanding debts after it has suffered an adverse shock to its economy. These episodes can take on the air of a crisis if the indebted country is required to reduce its consumption and investment to finance even partial repayment of its obligations at the same time that the country's creditors enjoy expanding consumption and investment. We cannot explain the fact that a borrowing country has had to reduce its consumption and investment to repay its debts simply by identifying the adverse shocks that have buffeted this borrowing country. These indebted countries are often relatively small players in the world economy. According to a complete markets model of lending, these countries should be able to share the risk of these adverse shocks with their creditors more than they seem to be able to do. The debt crisis of the 1980 's, although it is only one example, ${ }^{2}$ is a particularly good case illustrating the failure of international risk sharing: at the same time that the United States enjoyed a decade of strong economic growth, it received capital inflows from many countries which suffered their worst decade of economic decline since the Great Depression. Neither can we explain the lack of complete insurance made available through international loan contracts on the grounds that it is impossible to make the repayment of these contracts state contingent. Given the observation that in many cases borrowing countries have managed to negotiate a partial repayment of their debts, it is evident that some

\footnotetext{
${ }^{1}$ The author gratefully acknowledges helpful conversations with Patrick Kehoe, Ennio Stacchetti, Robert Townsend, Christopher Phelan, and the comments of two anonymous referees.

${ }^{2}$ Debt crises in the international bond markets were common in the nineteenth century. See Eichengreen and Portes (1986) and Lindert and Morton (1989) for discussion of these episodes and of the debt crises of the early twentieth century. These papers point out that the post-World War II era up to the early 1970 's was unusual in its lack of private international lending.
} 
degree of state contingency or risk sharing is built into international lending. ${ }^{3}$ This implicit risk sharing built into the process of debt recheduling and debt renegotiation, though, apparently is not complete enough to prevent the broad deviations from the predictions of simple models of risk sharing in complete markets that are associated with debt crises.

In this paper, I develop the idea that the pattern of capital flows, consumption, and investment associated with debt crises arises as part of the optimal pattern of capital flows when capital flows among countries are constrained by two market imperfections: moral hazard and the risk of repudiation. To introduce the moral hazard problem into my model, I assume that lenders cannot observe whether borrowers invest borrowed funds efficiently or simply consume them. To introduce the risk of repudiation, I assume that borrowers can at any time repudiate their debts. I show in this model that the borrower experiences capital outflows and suffers a fall in consumption and investment after low realizations of output as part of the constrained optimal pattern of capital flows. This result is consistent with the idea that the reversal of capital flows and the fall in consumption and investment that is seen in highly indebted countries during an international debt crisis may arise as part of the mechanism by which lenders induce borrowers to invest borrowed funds efficiently.

Specifically, I examine the optimal equilibrium pattern of capital flows in an environment in which there are two impediments to contracting that do not arise in the full-information, full-enforcement competitive model of international lending. The first impediment to contracting in the model I examine arises from the assumption that lenders cannot observe whether borrowers choose to invest or simply consume the proceeds of loans. With this assumption that lenders cannot perfectly monitor the amount that borrowers invest in this environment, for reasons of moral hazard, borrowers are unable to obtain loans which allow them to completely smooth their consumption across shocks to their output. The optimal pattern of lending in this environment must necessarily incorporate sufficient variation in the borrower's consumption as a result of variation in his output so as to provide him with the incentive to invest in increasing his output. The second impediment to contracting in this model arises from the assumption that lenders cannot appeal to some third party to enforce repayment of loans. With this assumption that loan repayment cannot be enforced arbitrarily, for fear of the risk of repudiation, lenders in this model must limit the size of repayments that they demand of borrowers and thus the size of loans that they are willing to make. I characterize the loan contract which best overcomes the moral hazard problem in lending within the constraints imposed by the risk of repudiation in a fully dynamic environment. I show that when low realizations of output are a sufficiently strong indicator of low past investment, then the optimal manner in which to provide incentives for the borrower to invest necessarily involves specifying that the borrower export

\footnotetext{
${ }^{3}$ See Grossman and van Huyck (1988) for a discussion of the implicit state contingency built into international debt contracts.
} 
capital and suffer a fall in consumption and investment after the lowest realizations of output.

My assumption that lenders cannot perfectly monitor the amounts that borrowers consume and invest is intended to capture the spirit of the various difficulties actual lenders have in monitoring a borrower's use of borrowed funds. For instance, if, as a result of government interference in markets, good market prices or shadow values are not readily available in the borrowing country for use in evaluating project performance, a lender may not be able to distinguish efficient investments made by the borrower from those containing a disguised component of consumption. ${ }^{4}$ Alternatively, in lending to a sovereign government, lenders may find it difficult to verify whether the full impact of that government's policies as a package is to further national adjustment to an adverse shock or to provide consumption subsidies to its citizens. My second assumption, that lenders cannot appeal to some third party to enforce repayment of loans, is a reflection of the fact that the borrowers are sovereign nations and may choose to repudiate their debts.

The technical approach I use in solving for the optimal equilibrium allocation in this environment is similar to the approach used by Abreu, Pearce, and Stacchetti $(1986,1990)$ for solving for the set of sequential equilibria of a repeated Cournot oligopoly game with imperfect monitoring and the approach taken by Spear and Srivastava (1987) for solving for the optimal contract in the repeated principal-agent incentive problem. In these other papers, the authors show that the problem of finding the set of payoffs from equilibrium strategies or incentive compatible contracts can be restated as a recursive problem. The optimal equilibrium outcomes also prove easier to analyze in this recursive setup. In the Cournot oligopoly problem, the optimal equilibrium outcome is Markov in last period's observed price, and in the principal-agent problem, the optimal long term contract is Markov in the new reservation utility promised to the agent in the remainder of the contract. The optimal contracting problem that I present in this paper is similar to these other models in that it can be restated in a recursive formulation. The model I use to describe international lending, though, differs from the standard repeated principal-agent problem in several important respects. Firstly, the borrower in this model is free to repudiate the contract at any time..$^{5}$ Most importantly, though, the borrower's output net of repayments of previous loans is a physical state variable which alters the feasible set of actions and payoffs that can be attained in any continuation of the lending problem, so that this is a dynamic rather than repeated environment. In this dynamic environment, the specification of the loan repayment schedule affects not only the borrower's payoff in the current round but also his prospects for future rounds by changing the state variable and thus the dynamic problem that is faced in the continuation. I show in this

\footnotetext{
${ }^{4}$ The borrower may disguise consumption as investment in a number of ways, including through the overemployment of labor or through outright fraud in the execution of an investment project.

${ }^{5}$ Phelan and Townsend (1991) discuss how to handle this type of constraint in the repeated principal-agent problem.
} 
dynamic environment that the optimal pattern of capital flows is Markov in this physical state variable and that it has a particularly simple structure. At each date, the continuation of the constrained Pareto optimal contract is itself constrained Pareto optimal and like the original contract, it awards all of the remaining surplus to the borrower. ${ }^{6}$ After I present this contracting problem in the appropriate recursive formulation, I use these results to show that the borrower necessarily suffers a capital outflow and a fall in consumption and investment when the lowest range of outputs are realized.

This paper is organized as follows. I describe the environment in Section 2. Then, in Section 3, I define the optimal contracting problem when allocations are constrained both by moral hazard and the risk of repudiation. In Section 4, I show that the optimal contracting problem can be equivalently restated in the space of current controls and value functions using an adaptation of the concepts of self-generation and factorization developed by Abreu, Pearce, and Stacchetti $(1986,1990)$. I provide a proof of existence of the optimal contract in Section 5 and I discuss conditions under which the value of the optimal contract as a function of the state variable is continuous. Using these results, I show that the problem of finding the constrained optimal contract can be stated in a recursive formulation as a functional equation in Section 6. In Section 7, I analyze the characteristics of the optimal debt contract by analyzing this functional equation. I present the proofs to Propositions 1 and 2 in the Appendix.

\section{THE ENVIRONMENT}

In this environment there are two types of agents. There is one infinitely-lived, risk-averse agent, whom I call the borrower. In addition to the borrower, there is a sequence of short-lived, risk-neutral agents, whom I call lenders, arranged in overlapping generations. A single lender is born in each period and each lender is alive for two periods. The borrower has an investment opportunity which offers stochastic returns. Increased investment by the borrower shifts the distribution of returns towards higher returns. Moral hazard constrains contracts between the borrower and the lenders because the borrower's consumption of the single good and the level of his investment are unobservable. The lenders are endowed with a large quantity of the single good in each period in which they are alive.

\footnotetext{
${ }^{6}$ There are several results related to the results here in the information and incentives literature. The following are of particular interest. Phelan and Townsend (1991) discuss how to obtain numerical solutions to the repeated principal-agent problem and demonstrate that the continuation of the optimal contract in the repeated principal-agent problem is not always Pareto optimal. Their methods may be useful in solving numerical examples of the present problem. Fudenberg, Holmstrom, and Milgrom (1990) demonstrate in the repeated principal-agent framework that if the agent has access to free borrowing and lending at a fixed interest rate, then the optimal long term contract can be rearranged into a sequence of optimal short term contracts. The borrower in my paper does not have access to unlimited borrowing and lending at a fixed interest rate. A similar result to the Fudenberg, Holmstrom, and Milgrom result still holds.
} 
The environment is described more specifically as follows. There is an infinite horizon. Time is discrete and denoted by $t=0,1,2, \ldots$ The single borrower is alive in all periods $t \geqslant 0$. The borrower is endowed with quantity $Y_{0}-d_{0}$ of the single good at time $t=0$. The consumption of the borrower in period $t$ is denoted $c_{t}$. Given investment by the borrower of $I_{t}$ units of the good at time $t$, the borrower's investment opportunity yields as output the random variable $Y_{t+1}$ (with support $\boldsymbol{Y}$ ) in units of the good at time $t+1$. There is one lender born each period and each lender lives two periods. The lender born in period $t$ is alive in periods $t$ and $t+1$. Each lender has an endowment of size $M$ in each period he is alive. The negative of the consumption net of endowment of the young lender born in period $t$ is denoted $d_{t+1}$. I refer to the quantity $b_{t}$ as a loan and quantity $d_{t+1}$ as a repayment without implying constraints on the signs of these variables. In keeping with this convention, I refer to the pair $\left(b_{t}, d_{t+1}\left(Y_{t+1}\right)\right)$ as a loan contract and the function $d_{t+1}\left(Y_{t+1}\right)$ as a repayment schedule. ${ }^{7}$

An allocation in this environment is defined to be a plan which specifies the disposition of the current output $Y_{t}$ between current consumption for the borrower, the old lender, the young lender, and investment in the storage technology. The plan for the disposition of current output may depend on the entire observable history of realization of outputs, loans, and repayments. For convenience, I choose to use the variable $Q_{t}=Y_{t}-d_{t}$ to summarize the history dependence of the allocation. Thus, an allocation $\sigma$ specifies the consumption of the borrower, $c$, investment, $I$, loans, $b$, and repayment schedules, $d$, written:

$$
\sigma=\left\{c_{t}\left(Q^{t}\right), I_{t}\left(Q^{t}\right), b_{t}\left(Q^{t}\right), d_{t+1}\left(Y_{t+1} ; Q^{t}\right)\right\}_{t=0}^{\infty}
$$

where $Q^{t}=\left(Q_{0}, Q_{1}, \ldots, Q_{t}\right)$. An allocation is marked with initial conditions $Y_{0}, Q_{0}, d_{0}$ and $Q_{0}=Y_{0}-d_{0}$.

Denote the consumption component of the allocation by $\sigma^{c}$, the investment component by $\sigma^{I}$, and so on. Denote the actions specified by the allocation in time $t$ and state $Q^{t}$ by $\sigma_{t}\left(Q^{t}\right)$.

Definition: An allocation is feasible if for all $t \geqslant 0, Q^{t}, Y_{t} \in \boldsymbol{Y}$ :

$$
c_{t}\left(Q^{t}\right)-b_{t}\left(Q^{t}\right)+I_{t}\left(Q^{t}\right) \leqslant Y_{t}-d_{t}\left(Y_{t}\right)
$$

with $c_{t}\left(Q^{t}\right), I_{t}\left(Q^{t}\right) \geqslant 0, b_{t},-d_{t} \leqslant M$, and $Y_{0}, Q_{0}, d_{0}$ given. By convention $d_{0}=0$.

The following three assumptions describe the structure of returns from the borrower's investment opportunity.

\footnotetext{
${ }^{7}$ I model loans as having state contingent repayment schedules in the spirit of the reality that international loans, while nominally not state contingent, are made state contingent through frequent reschedulings of repayments coming due. See Grossman and van Huyck (1988) for a discussion of the implicit state contingency built into international lending. The central issue being explored in this paper is the question of why this implicit mechanism for making international loan contracts state contingent fails to provide borrowing countries with full insurance against adverse shocks.
} 
Assumption 1: The support of realizations of output $Y$ from the storage technology each period is the finite set $\boldsymbol{Y}=\left\{Y_{1}, Y_{2}, \ldots, Y_{N}\right\}$ with $Y_{n} \geqslant Y_{1}>0$.

Assumption 2: The distribution of output in any period $t+1$ depends only on the investment level in period $t$. Write the vector of probabilities of realization of output level $Y^{\prime}$ tomorrow given investment $I$ today, as $g\left(Y^{\prime} ; I\right)=$ $\left(g\left(Y_{1}^{\prime}, I\right), \ldots, g\left(Y_{N}^{\prime}, I\right)\right)$.

Assumption 3: $g\left(Y_{i}^{\prime} ; I\right)>0$ for all $i \in\{i, \ldots, N\}$ and $I \in I$.

This assumption guarantees that there are no observations of $Y^{\prime}$ that allow the lenders to infer with certainty that the borrower did or did not invest at some level $I$.

In order to focus attention on the borrower's side of the optimal contracting problem, I impose two additional assumptions about the lenders in this environment. First, I assume that lenders can bind themselves when young to carry out the terms of a contract when they are old. This assumption ensures that the borrower can costlessly enforce his right to make withdrawals in those contingencies in which a negative repayment $d_{t+1}$ is called for. One should think of the lenders as banks which for reasons outside the model find it too costly to renege on their depositors. Second, I assume that an old lender who has suffered a repudiation of his loan may costlessly seize any deposits the borrower might make with a future lender as compensation towards his loss. This right can be sold from one generation of lenders to the next until the loss has been entirely compensated. This assumption prevents the borrower from playing one lender off against another through a strategy of repudiating a repayment to the current old lender and then using the funds intended for repayment to establish a deposit with a future young lender against which he might make withdrawals to smooth consumption without applying for future loans. ${ }^{8}$

The borrower has preferences over allocations denoted by $U^{B}(\sigma)$ and characterized by

$$
U^{B}(\sigma)=(1-\delta) E_{0}^{\sigma} \sum_{t=0}^{\infty} \delta^{t} u\left(c_{t}\left(Q^{t}\right)\right)
$$

with $u$ bounded above by $\bar{u}, u^{\prime}>0, u^{\prime}(0)=+\infty$, and $u^{\prime \prime}<0$. $E_{0}^{\sigma}$ denotes the mathematical expectation conditional on the information available at time 0 , taken with respect to the probability measure induced by the allocation $\sigma$. The lender born in period $t, t \geqslant 0$, has preferences over the expected value of his consumption, where the expectation is taken conditional upon the realization of $Q^{t}$ at the time of his birth. These preferences are denoted by $U^{L_{t}}\left(\left.\sigma\right|_{Q^{t}}\right)$ and

\footnotetext{
${ }^{8}$ See Bulow and Rogoff (1988) for a detailed discussion as to why this assumption is necessary to support any lending at all in this environment.
} 
characterized by

$$
U^{L_{t}}\left(\left.\sigma\right|_{Q^{t}}\right)=-b_{t}\left(Q^{t}\right)+\delta \sum_{Y_{t+1} \in \boldsymbol{Y}} d_{t+1}\left(Y_{t+1} ; Q^{t}\right) g\left(Y_{t+1} ; I_{t}\left(Q^{t}\right)\right)
$$

where $\left.\sigma\right|_{Q^{t}}$ is the continuation of an allocation after $Q^{t}$ has been realized.

I confine myself to examining allocations which are both feasible and which provide all parties to the contract supporting the allocation with at least as much utility as could be obtained by not contracting at all. The reservation utility of the lenders in this environment is zero; they can always receive zero consumption net of endowment by not entering into any contracts. The reservation utility of the borrower is defined by the expected utility he can receive refusing all loans and consuming and investing in the storage technology on his own. This reservation utility that the borrower can obtain in autarky is the solution to the following programming problem:

$$
U_{\text {aut }}^{B}(Z)=\max _{I}(1-\delta) u(Z-I)+\delta \sum_{Y^{\prime} \in \boldsymbol{Y}} U_{\text {aut }}^{B}\left(Y^{\prime}\right) g\left(Y^{\prime} ; I\right) .
$$

Assumption 4: $(1-\delta) u(0)+\delta \bar{u}<U_{\text {aut }}^{B}\left(Y_{1}\right)$.

This condition ensures that there are levels of current consumption so low that the borrower prefers the autarkic allocation to an allocation which specifies these low levels of current consumption, regardless of what levels of consumption were to be offered in the future. I use this assumption to place a lower bound on the level of the state variable that can be considered in an equilibrium loan contract.

An allocation cannot be supported by contracts in equilibrium unless it provides each agent with expected utility at least as great as his reservation utility in every round of contracting. This constraint is expressed as follows.

Definition: An allocation is individually rational if

$$
U^{B}\left(\left.\sigma\right|_{Q^{t}}\right) \geqslant U_{\text {aut }}^{B}\left(Q_{t}\right) \quad \text { and } \quad U^{L_{t}}\left(\left.\sigma\right|_{Q^{t}}\right) \geqslant 0
$$

for all $Q^{t}, t \geqslant 0$.

\section{THE CONSTRAINED PARETO PROBLEM}

In this section I define the constraints on the set of allocations that are imposed by the problems of moral hazard and the risk of repudiation and then I set up the problem of finding the constrained Pareto optimal pattern of capital flows. I begin with the constraints imposed by the risk of repudiation.

To define the set of allocations which are free from the risk of repudiation, I must describe explicitly the range of punishments that the lenders can impose upon the borrower for repudiation. ${ }^{9}$ In this environment, the lenders have no

\footnotetext{
${ }^{9} \mathrm{By}$ assumption it is unnecessary to consider the possibility that the lenders will repudiate their contracts.
} 
direct sanctions with which to punish the borrower if he repudiates his debts. ${ }^{10}$ On the other hand, the lenders can indirectly punish the borrower for repudiation by refusing him further loans. Facing lenders who refuse to lend, the borrower obtains his autarkic utility as his minimax payoff. We also see that lenders can credibly refuse to provide further loans $(b>0)$ in a perfect equilibrium as follows. If, in any period, all future lenders plan to deny credit to the borrower, then the borrower finds it in his interest to repudiate any outstanding loans. Given this fact, a lender who recognizes that all future lenders will not lend must refuse to accept any contract with the borrower that specifies $b>0$ or any $d^{\prime}\left(Y^{\prime}\right)>0$ since he knows that the borrower will repudiate any positive repayments specified by that contract. Finally, given our assumptions about the lenders, we see that the borrower cannot establish savings deposits $(b<0$ or any $\left.d^{\prime}\left(Y^{\prime}\right)<0\right)$ to smooth his consumption after repudiating his debts since these deposits are subject to seizure. Thus, the worst punishment that the lenders can impose upon a borrower who repudiates his debts is the borrower's autarkic utility.

I characterize allocations which can be supported by loan contracts under the threat of repudiation as follows.

DeFinition: An allocation $\sigma$ is immune from the threat of repudiation if for all $t \geqslant 0, Q^{t}, Y_{t+1} \in Y$, the continuation allocation $\left.\sigma\right|_{Q^{t} ; Y_{t+1}}$, after the realization of output $Y_{t+1}$ from the storage technology, satisfies:

$$
U^{B}\left(\left.\sigma\right|_{Q^{t} ; Y_{t+1}}\right) \geqslant U_{a u t}^{B}\left(Y_{t+1}\right)
$$

An allocation satisfies the constraints imposed by the problem of moral hazard if the borrower finds it optimal to carry out the consumption and investment plan specified in the allocation when he takes the lending and repayment plans specified as given:

Definition: An allocation $\sigma$ is incentive compatible if for all feasible allocations $\sigma^{\prime}=\left(\sigma^{c \prime}, \sigma^{I \prime}, \sigma^{b}, \sigma^{d}\right)$ (with the components $\sigma^{b}$ and $\sigma^{d}$ unchanged):

$$
U^{B}(\sigma) \geqslant U^{B}\left(\sigma^{\prime}\right) \text {. }
$$

I can now state the optimal contracting problem to be studied in this paper.

Definition: An allocation $\sigma$ is constrained Pareto optimal if it maximizes the borrower's payoff $U^{B}(\sigma)$ subject to the constraints of (1) feasibility, (2) individual rationality, (3) immunity from the threat of repudiation, and (4) incentive compatibility.

\footnotetext{
${ }^{10}$ See Bulow and Rogoff (1989) for a model of international lending in which the repayment of sovereign debt is supported by the threat of direct sanctions.
} 
The difficult part of solving this program is understanding how to handle the last incentive compatibility constraint. If positive investment is specified in an equilibrium allocation, then full insurance is not incentive compatible. Under full insurance, the borrower will invest nothing because his payoff does not depend upon the output from his investment opportunity and thus does not depend upon his level of investment. It is clear, then, that the utility that the borrower receives from the continuation of the equilibrium allocation must vary sufficiently with the results of some statistical test on the realization of output $Y^{\prime}$ so as to induce the borrower to make the equilibrium level of investment. Because the borrower will be choosing investment in anticipation of the test on output that determines his continuation payoff, standard results from hypothesis testing do not apply. When this strategic consideration is taken into account, the optimal statistical test on output and the optimal manner in which to make the borrower's continuation payoff depend on the results of that test is not obvious.

We know from study of the repeated Cournot oligopoly problem with imperfect monitoring ${ }^{11}$ and the repeated principal-agent problem ${ }^{12}$ that this incentive problem can be reformulated as a recursive problem with a solution which is Markov if only the appropriate state variable can be found. In the repeated oligopoly problem, this state variable is the price observed in the previous period. In the repeated principal-agent problem, on the other hand, this state variable is the reservation utility promised to the agent for the remainder of the problem. In the next section, I demonstrate that the problem stated here is recursive once $Q_{t}$, the amount of the consumption good the borrower has left after paying outstanding loans, is taken as the state variable.

\section{THE TRANSFORMED PARETO PROBLEM}

In this section, I demonstrate that the correspondence of payoffs which the borrower can obtain from allocations which satisfy the constraints of the optimal contracting problem above can be defined recursively using an adaptation of the notations of admissibility, self-generation, and factorization of Abreu, Pearce, and Stacchetti $(1986,1990) .{ }^{13}$ In Section 6, I will use this result to show that the constrained Pareto optimal allocation itself can be found as part of the solution of a functional equation similar to a Bellman's equation and that the optimal allocation is necessarily Markov in structure.

The central ideas behind the results of this section are very similar to those behind dynamic programming. I seek to characterize the correspondence which defines the set of payoffs that the borrower can obtain from allocations which satisfy constraints (1)-(4) at each initial value of the state variable $Q$. I call this

\footnotetext{
${ }_{11}^{11}$ See Abreu, Pearce, and Stacchetti $(1986,1990)$.

${ }^{12}$ See Spear and Srivastava (1987) and Phelan and Townsend (1991).

${ }^{13}$ For those who are familiar with the techniques of Abreu, Pearce, and Stacchetti $(1986,1990)$, the results of this section are the natural extensions of their propositions self-generation and factorization to this problem with a state variable. The definition of admissibility has been generalized to include the state variable. Otherwise the proofs proceed along the lines of the proofs of Propositions 1 and 2 in their paper and will be included here in the Appendix.
} 
correspondence the borrower's utility possibility correspondence. I observe that any payoff that can be obtained for the borrower from an allocation which satisfies constraints (1)-(4) can be factored into a payoff from the actions taken in the first period and the expectation over the payoffs to the borrower from the actions to be taken from the second period onwards, where these actions, of course, are conditional on the value of output less repayments realized at the end of the period. More simply, those payoffs to the borrower from actions taken in the second period onwards can be summarized by a continuation value function which takes on the value to the borrower from the continuation of the allocation after every possible realization of $Q_{1}$. Because the constraints (1)-(4) are recursive, the continuation of any allocation which satisfies constraints (1)-(4) also satisfies these same constraints. Thus every allocation which satisfies constraints (1)-(4) yields a payoff to the borrower in the utility possibility correspondence which can be factored into a payoff to the borrower from current actions and an expectation over a continuation value function which is itself a selection from the borrower's utility possibility correspondence.

I also prove a converse of this property. Specifically, I show that any payoff that can be obtained for the borrower through current controls and some continuation value function which satisfy one period versions of constraints (1)-(4) and for which the value function is a selection from the borrower's utility possibility correspondence can also be obtained through some allocation which satisfies the original constraints (1)-(4). I call a set of current controls and continuation value function admissible if they satisfy one period versions of constraints (1)-(4) and if the value function is a selection from the borrower's utility possibility correspondence. Armed with this characterization of the borrower's utility possibility correspondence in terms of admissible controls and value functions, I am able to restate the optimal contracting problem as a recursive problem in a space of current controls and value functions.

Define the borrower's utility possibility correspondence, $V$, with domain $Q$ to be, for each initial value of $Q \in Q$, the set of payoffs which the borrower can obtain from allocations which satisfy constraints (1)-(4). That is, for each value of $Q$,

$$
V(Q)=\left\{U^{B}(\sigma) \mid \sigma \text { satisfies (1)-(4) and } Q_{0}=Q\right\}
$$

The correspondence $V$ is not empty-valued since $U_{a u t}^{B}(Q) \in V(Q)$ for all $Q$. I characterize this correspondence $V$ in Propositions 1 and 2 of this section.

I begin by defining admissibility with respect to an arbitrary correspondence of payoffs for the borrower. Let $W$ be any correspondence defined over domain $Q$, with $W(Q)$ nonempty-valued and uniformly bounded for all values in the domain. Define a set of current controls to be the vector $A=\left(c, I, b, d^{\prime}\right)$ where $c, I$, and $b$ are scalars and $d^{\prime}: \boldsymbol{Y} \rightarrow \boldsymbol{R}$. Define a function $U$ to be a continuation value function if it is a selection from the correspondence $W$, i.e. $U: Q \rightarrow \boldsymbol{R}$, with $U\left(Q^{\prime}\right) \in W\left(Q^{\prime}\right)$ for all values of $Q^{\prime}$. 
Definition: The pair $(A, U)$ of current controls and continuation value function, is admissible with respect to $W$ at $Q$ if it satisfies the following four conditions:

$$
\begin{aligned}
& c+I-b \leqslant Q, \quad b,-d^{\prime}\left(Y^{\prime}\right) \leqslant M, \quad c, I \geqslant 0, \\
& (1-\delta) u(c)+\delta \sum_{Y^{\prime} \in \boldsymbol{Y}} U\left(Q^{\prime}\right) g\left(Y^{\prime} ; I\right) \geqslant U_{\text {aut }}^{B}(Q)
\end{aligned}
$$

and

$$
b \leqslant \delta \sum_{Y^{\prime} \in \boldsymbol{Y}} d^{\prime}\left(Y^{\prime}\right) g\left(Y^{\prime} ; I\right)
$$

for all $Y^{\prime} \in Y^{\prime}$,

$$
\begin{aligned}
& U\left(Y^{\prime}-d^{\prime}\left(Y^{\prime}\right)\right) \geqslant U_{a u t}^{B}\left(Y^{\prime}\right), \\
& I \in \underset{\tilde{I}}{\arg \max }(1-\delta) u(Q+b-\tilde{I})+\delta \sum_{Y^{\prime} \in \boldsymbol{Y}} U\left(Y^{\prime}-d^{\prime}\left(Y^{\prime}\right)\right) g\left(Y^{\prime} ; \tilde{I}\right) .
\end{aligned}
$$

Conditions $\left(1^{\prime}\right)-\left(4^{\prime}\right)$ are the analogues of feasibility, individual rationality, immunity from the threat of repudiation, and incentive compatibility stated in terms of these current controls and continuation value functions.

Denote the payoff to the borrower generated by a pair $(A, U)$ by $E(A, U)(Q)$, where

$$
E(A, U)(Q)=(1-\delta) u(c)+\delta \sum_{Y^{\prime} \in \boldsymbol{Y}} U\left(Y^{\prime}-d^{\prime}\left(Y^{\prime}\right)\right) g\left(Y^{\prime} ; I\right) .
$$

Denote the set of payoffs that can be generated by pairs $(A, U)$ admissible with respect to $W$ at $Q$ by $B(W)(Q)$, where

$$
\begin{aligned}
B(W)(Q)=\{ & E(A, U)(Q) \text { such that }(A, U) \\
& \text { admissible with respect to } W \text { at } Q\} .
\end{aligned}
$$

Definition: The correspondence $W$ is self-generating if for all $Q \in \boldsymbol{Q}$

$$
W(Q) \subseteq B(W)(Q) .
$$

Proposition 1 (Self-generation): If $W$ is self-generating, then for all $Q \in Q$,

$$
B(W)(Q) \subseteq V(Q)
$$

Proposition 2 (Factorization): $V(Q) \subseteq B(V)(Q)$ for all $Q$.

The formal proofs of these propositions are straightforward adaptations of the proofs given by Abreu, Pearce, and Stacchetti $(1986,1990)$ and are included in the Appendix. 
The value of the optimal contract as a function of the state variable $\bar{V}(Q)$ is defined pointwise:

$$
\bar{V}(Q)=\sup _{v \in V(Q)} v .
$$

We see from Propositions 1 and 2 that $\bar{V}(Q)$ is characterized by the program:

$$
\bar{V}(Q)=\sup _{A, U}(1-\delta) u(c)+\delta \sum_{Y^{\prime} \in \boldsymbol{Y}} U\left(Y^{\prime}-d^{\prime}\left(Y^{\prime}\right)\right) g\left(Y^{\prime} ; I\right)
$$

subject to the constraint that $(A, U)$ be admissible with respect to $V$ at $Q=Q_{0} \cdot{ }^{14}$

\section{ON THE EXISTENCE AND CONTINUITY OF THE OPTIMAL CONTRACT}

In this section I demonstrate the existence of an optimal contract and discuss conditions under which the function, $\bar{V}(Q)$, which defines the value of the optimal contract for each initial value of the state variable, is continuous. These results are used in the next section to arrive at a stronger characterization of the optimal debt contract.

Given the assumption that $\boldsymbol{Y}$ is finite, $\mathrm{I}$ find it convenient in analyzing the question of existence of the optimal contract to work directly with the vector

$$
U_{d}=\left(U\left(Y_{1}^{\prime}-d^{\prime}\left(Y_{1}^{\prime}\right)\right), \ldots, U\left(\dot{Y}_{N}^{\prime}-d^{\prime}\left(Y_{N}^{\prime}\right)\right)\right)
$$

that results from the composition of a value function and a repayment schedule. Define $U_{d}$, a vector in $\boldsymbol{R}^{N}$, to be a composition of a value function and a repayment schedule with respect to a correspondence $W$ if

$$
U_{d}\left(Y_{i}^{\prime}\right) \in W\left(Y_{i}^{\prime}-d^{\prime}\left(Y_{i}^{\prime}\right)\right) \quad \forall Y_{i}^{\prime} \in Y .
$$

LEMMA 1: If $W$ has a compact graph, then $B(W)$ has a compact graph.

Proof: First, I demonstrate that the correspondence $B(W)$ has a bounded graph. Let $W$ be a correspondence with a compact graph. By feasibility, consumption, investment, lending and repayments, are all bounded above and below. By Assumption 4, the state variable $Q$ denoting output net of repayments is bounded below, and by feasibility it is bounded above by $Y_{N}+M$. Therefore, our choice space of vectors $\left(A, U_{d}\right)$ which are admissible with respect to $W$ at some $Q$ is contained in a bounded subset of a finite dimensional Euclidean space. Redefine the payoff functional $E$ to accommodate compositions of continuation value functions and repayment schedules in the natural manner. This payoff functional is continuous in all its arguments since $g\left(Y^{\prime} ; I\right)$ is continuous in $I$ by Assumption 2. Thus $B(W)$ has a bounded graph.

Second, I demonstrate that $B(W)$ has a closed graph. The only constraints defining $B(W)$ which need to be restated to accommodate compositions of

\footnotetext{
${ }^{14}$ Since we are maximizing the payoff to the borrower, the individual rationality constraint for the borrower is never binding in this program. The individual rationality constraint in the definition of admissibility can be simplified to apply only to the lender.
} 
value functions and repayment schedules $U_{d}$ are constraints $\left(3^{\prime}\right)-\left(5^{\prime}\right)$ and they are as follows:

$$
\begin{aligned}
& U_{d}\left(Y_{i}^{\prime}\right) \geqslant U_{\text {aut }}^{b}\left(Y_{i}^{\prime}\right) \quad \forall Y_{i}^{\prime}, \\
& I \in \underset{\tilde{I} \in[0, Q+b]}{\arg \max }(1-\delta) u(Q+b-\tilde{I})+\delta \sum_{i=1}^{N} U_{d}\left(Y_{i}^{\prime}\right) g\left(Y_{i}^{\prime} ; \tilde{I}\right), \\
& U_{d}\left(Y_{i}\right) \in W\left(Y_{i}^{\prime}-d^{\prime}\left(Y_{i}^{\prime}\right)\right) \quad \forall Y_{i} .
\end{aligned}
$$

Let $\left\{w_{n}, Q_{n}\right\}$ be a sequence in the graph of $B(W)$ which converges to a point $(w, Q)$. By the definition of $B(W)$, there exists a sequence of pairs of controls and value functions composed with repayment schedules, $\left\{A_{n}, U_{d n}\right\}$, each of which satisfies constraints $\left(1^{\prime}\right)-\left(5^{\prime}\right)$ at $Q_{n}$ and has payoff $E\left(A_{n}, U_{d n}\right)\left(Q_{n}\right)=w_{n}$. Because the space of admissable controls and compositions of value functions and repayment schedules is bounded, we may assume this sequence of pairs converges to some limit point $\left(A, U_{d}\right)$. By the continuity of $E$, we have $E\left(A, U_{d}\right)(Q)=w$. Constraints $\left(1^{\prime}\right)-\left(3^{\prime}\right)$ are closed so that they are satisfied in the limit as well. The correspondence $I^{*}\left(Q+b, U_{d}\right)$ defined by the $\operatorname{argmax}$ of constraint $\left(4^{\prime}\right)$ is upper hemi-continuous by the maximum theorem. Thus $I \in$ $I^{*}\left(Q+b, U_{d}\right)$ is satisfied in the limit so constraint $\left(4^{\prime}\right)$ is also closed. Finally, constraint $\left(5^{\prime}\right)$ is satisfied in the limit since $W$ has a compact graph. Thus $(w, Q)$ is in the graph of $B(W)$.

LEMMA 2: If $\operatorname{graph}\left(W_{1}\right) \subseteq \operatorname{graph}\left(W_{2}\right)$, then $\operatorname{graph}\left(B\left(W_{1}\right)\right) \subseteq \operatorname{graph}\left(B\left(W_{2}\right)\right)$.

Proof: The constraints defining $B\left(W_{1}\right)$ are contained in those defining $B\left(W_{2}\right)$.

Proposition 3: V has a compact graph.

Proof: Define the correspondence $V_{1}$ to satisfy

$$
\operatorname{graph}\left(V_{1}\right)=\operatorname{closure}(\operatorname{graph}(V)) .
$$

By definition $\operatorname{graph}(V) \subseteq \operatorname{graph}\left(V_{1}\right)$. By Lemma $2, \operatorname{graph}(B(V)) \subseteq \operatorname{graph}\left(B\left(V_{1}\right)\right)$. By Propositions 1 and 2, graph $(B(V))=\operatorname{graph}(V)$. By Lemma 1, $\operatorname{graph}\left(B\left(V_{1}\right)\right)$ is closed. Because graph $\left(V_{1}\right)$ is the smallest closed set containing $\operatorname{graph}(V)$, $\operatorname{graph}\left(V_{1}\right) \subseteq \operatorname{graph}\left(B\left(V_{1}\right)\right)$, which implies that $V_{1}$ is self-generating. By Proposition 1, $\operatorname{graph}\left(V_{1}\right) \subseteq \operatorname{graph}(V)$. Therefore, $V$ has a closed and thus compact graph.

By Proposition 3, we have that for each $Q$, an optimal loan contract exists. In the remainder of this section, I will discuss conditions under which the value of the optimal contract, $\bar{V}(Q)$, is continuous in the state variable. I begin with an assumption and a lemma showing that the set of maximizing arguments of constraint (4') is single-valued. 
Assumption 5: Assume that the distribution of output given investment $g\left(Y^{\prime} ; I\right)$ is given by the convex combination of two underlying distributions $g_{0}\left(Y^{\prime}\right)$ and $g_{1}\left(Y^{\prime}\right)$ as follows:

$$
g\left(Y^{\prime} ; I\right)=\lambda(I) g_{0}\left(Y^{\prime}\right)+(1-\lambda(I)) g_{1}\left(Y^{\prime}\right)
$$

with $\left(g_{0}\left(Y_{i}^{\prime}\right) / g_{1}\left(Y_{i}^{\prime}\right)\right)$ monotone in $i, 0 \leqslant \lambda(I) \leqslant 1, \lambda^{\prime}(I)>0$, and $\lambda^{\prime \prime}(I) \leqslant 0$ for all $I^{15}$

Lemma 3: Let $g\left(Y^{\prime} ; I\right)$ be defined as in Assumption 5. Then, the correspondence $I^{*}\left(Q+b, U_{d}\right)$ defined by constraint $\left(4^{\prime}\right)$ is single valued.

Proof: The first and second derivatives of constraint (4') with respect to $I$ are as follows:

$$
\begin{aligned}
& -(1-\delta) u^{\prime}(Q+b-I)+\delta \lambda^{\prime}(I) \sum_{i=1}^{N} U_{d}\left(Y_{i}^{\prime}\right)\left(g_{0}\left(Y_{i}^{\prime}\right)-g_{1}\left(Y_{i}^{\prime}\right)\right), \\
& (1-\delta) u^{\prime \prime}(Q+b-I)+\delta \lambda^{\prime \prime}(I) \sum_{i=1}^{N} U_{d}\left(Y_{i}^{\prime}\right)\left(g_{0}\left(Y_{i}^{\prime}\right)-g_{1}\left(Y_{i}^{\prime}\right)\right) .
\end{aligned}
$$

If $\sum_{i=1}^{N} U_{d}\left(Y_{i}^{\prime}\right)\left(g_{0}\left(Y_{i}^{\prime}\right)-g_{1}\left(Y_{i}^{\prime}\right)\right) \geqslant 0$, then the expression being maximized is strictly concave in $I$ and thus has a unique maximizing argument. If $\sum_{i=1}^{N} U_{d}\left(Y_{i}^{\prime}\right)\left(g_{0}\left(Y_{i}^{\prime}\right)-g_{1}\left(Y_{i}^{\prime}\right)\right)<0$, then the expression being maximized is strictly decreasing in $I$ and thus is maximized at $I=0$.

With Lemma 3, I may write the solution to constraint (4') as a continuous function $I^{*}\left(Q+b, U_{d}\right)$. Substitute this function into constraint $\left(2^{\prime}\right)$ to express the present value of a loan contract as a function of $b$, given $Q, d^{\prime}$, and $U_{d}$ :

$$
L^{*}\left(b ; d^{\prime}, U_{d}, Q\right)=-b+\delta \sum_{i=1}^{N} d^{\prime}\left(Y_{i}^{\prime}\right) g\left(Y_{i}^{\prime} ; I^{*}\left(Q+b, U_{d}\right)\right) \geqslant 0 \text {. }
$$

Notice that $L^{*}$ is continuous in all its arguments.

Proposition 4: Assume that for any pair $\left(A, U_{d}\right)$ which satisfies $L^{*}\left(b ; d^{\prime}, U_{d}, Q\right) \geqslant 0$ and any $\delta_{1}>0$, there exists $a b_{1}$ with $\left|b_{1}-b\right|<\delta_{1}$ and $L^{*}\left(b_{1} ; d^{\prime}, U_{d}, Q\right)>0$. Then $V$ and $\bar{V}$ are continuous.

Proof: I have shown that $V$ has a compact graph, which implies that $V$ is upper hemi-continuous. I need to show now that $V$ is lower hemi-continuous. Let $v \in V(Q)$ and $\left(A, U_{d}\right)$ be a pair admissible with respect to $V$ at $Q$ with $E\left(A, U_{d}\right)(Q)=v$. Take $\varepsilon>0$. Since the payoff functional $E$ and investment function $I^{*}$ are continuous in all their arguments, we can find a $\delta_{1}>0$ such that for all $b_{1}$ with $\left|b_{1}-b\right|<\delta_{1}$ and $I_{1}=I^{*}\left(Q+b_{1}, U_{\mathrm{d}}\right), c_{1}=Q+b_{1}-I_{1}$, we have $\left|E\left(A_{1}, U_{d}\right)(Q)-E\left(A, U_{d}\right)(Q)\right|<\varepsilon / 2$. Furthermore, we have assumed that for

\footnotetext{
${ }^{15}$ This assumption about the structure of the distribution of output given investment is taken
} from Grossman and Hart (1983). It justifies the use of the first order condition in this case. 
one particular such $b_{1}$, we have $L^{*}\left(b_{1} ; d^{\prime}, U_{d}, Q\right)>0$. Since $L^{*}$ is continuous in $Q$, we may find a $\delta>0$ such that for all $Q_{1}$ with $\left|Q_{1}-Q\right|<\delta$, we have $L^{*}\left(b_{1} ; d^{\prime}, U_{d}, Q_{1}\right) \geqslant 0$ and $\left|E\left(A_{1}, U_{d}\right)\left(Q_{1}\right)-E\left(A_{1}, U_{d}\right)(Q)\right|<\varepsilon / 2$. By the triangle inequality, for all $Q_{1}$ with $\left|Q_{1}-Q\right|<\delta,\left|E\left(A_{1}, U_{d}\right)\left(Q_{1}\right)-E\left(A_{1}, U_{d}\right)(Q)\right|<\varepsilon$. Furthermore, $\left(A_{1}, U_{d}\right)$ is admissible with respect to $V$ at $Q_{1}$. Therefore, $V$ is lower hemi-continuous and $\bar{V}(Q)$ is continuous.

From Proposition 4 , it is clear that the correspondence $V$ may fail to be continuous when $L^{*}\left(b ; d^{\prime}, U_{d}, Q\right)$ attains a local maximum in $b$ at zero. I present the following example in which $L^{*}\left(b ; d^{\prime}, U_{d}, Q\right)$ satisfies the conditions of Proposition 4. When $\lambda(I)$ is linear in $I$ and $u(c)=\log (c)$, then $I^{*}\left(Q+b, U_{d}\right)$ and $L^{*}\left(b ; d^{\prime}, U_{d}, Q\right)$ are linear in $b$. The function $L^{*}\left(b ; d^{\prime}, U_{d}, Q\right)$ may still prove to be identically zero, but in this case, an argument similar to the argument of Proposition 4 suffices to show that $V$ contains no isolated points.

\section{THE PARETO PROBLEM AS A FUNCTIONAL EQUATION}

In this section, I find conditions under which we may rewrite the optimal contracting problem given in program (P) as a functional equation. This characterization of the optimal contract via a functional equation yields the strong implication that the long term relationship between the borrower and the lenders can be governed optimally by a sequence of contracts which are optimal in the short term: the continuation of the constrained optimal contract is always itself constrained optimal. I state the result in Proposition 5.

Proposition 5: Assume that the value function $\bar{V}$ is continuous. Then the continuation value function $\hat{U}$ which solves the program $(\mathrm{P})$ necessarily satisfies $\hat{U}=\bar{V}$.

Proof: The proof proceeds by contradiction. Let $(A, \hat{U})$ be an admissible pair with $U\left(Y_{n}^{\prime}-d^{\prime}\left(Y_{n}^{\prime}\right)\right)<\bar{V}\left(Y_{n}^{\prime}-d^{\prime}\left(Y_{n}^{\prime}\right)\right)$ for some $n$. Construct an alternative pair $(\tilde{A}, \bar{V})$ as follows: choose $\tilde{c}=c, \tilde{I}=I, \tilde{b}=b$ and for each $Y^{\prime} \in \boldsymbol{Y}$ choose $\tilde{d}^{\prime}\left(Y^{\prime}\right) \geqslant d^{\prime}\left(Y^{\prime}\right)$ to solve $\bar{V}\left(Y^{\prime}-\tilde{d}^{\prime}\left(Y^{\prime}\right)\right)=U\left(Y^{\prime}-d^{\prime}\left(Y^{\prime}\right)\right)$. That the repayments schedule $\tilde{d}^{\prime}\left(Y^{\prime}\right)$ is well defined is seen as follows. Feasibility constrains consumption to approach zero as $Q$ becomes sufficiently low. By Assumption 4, there must then exist a value of the state $Q^{*}$ such that $\bar{V}\left(Q^{*}\right)<U_{a u t}^{B}\left(Y_{1}\right)$. By the admissibility of $\hat{U}, \hat{U}\left(Y^{\prime}-d^{\prime}\left(Y^{\prime}\right)\right) \geqslant U_{a u t}^{B}\left(Y_{1}\right)$ for all $Y^{\prime}$, and for all $Q^{\prime}, \hat{U}\left(Q^{\prime}\right) \leqslant$ $\bar{V}\left(Q^{\prime}\right)$. Since $\bar{V}(Q)$ is continuous, for each $Q^{\prime}$, there must exist one $\tilde{Q}$ such that $\bar{V}(\hat{Q})=\hat{U}\left(Q^{\prime}\right)$. See Figure 1 for a picture of how the alternate pair is formed. The pair $(\tilde{A}, \bar{V})$ satisfies constraints $\left(1^{\prime}\right)-\left(4^{\prime}\right)$ of admissibility and, since $\bar{V}\left(Q^{\prime}\right) \in$ $V\left(Q^{\prime}\right) \forall Q^{\prime}$, is thus admissible. Also, we have $E(A, U)(Q)=E(\tilde{A}, \bar{V})(Q)$. Clearly $\bar{V}$ is increasing. Thus, if for some $Y^{\prime}, \bar{V}\left(Y^{\prime}-d^{\prime}\left(Y^{\prime}\right)\right)>\hat{U}\left(Y^{\prime}-d^{\prime}\left(Y^{\prime}\right)\right)$, then

$$
\sum_{Y^{\prime} \in \boldsymbol{Y}} \tilde{d}^{\prime}\left(Y^{\prime}\right) g\left(Y^{\prime} ; I\right)>\sum_{Y^{\prime} \in \boldsymbol{Y}} d^{\prime}\left(Y^{\prime}\right) g\left(Y^{\prime} ; I\right)
$$

so that constraint $\left(2^{\prime}\right)$ is relaxed. We see that our ability to relax this constraint 


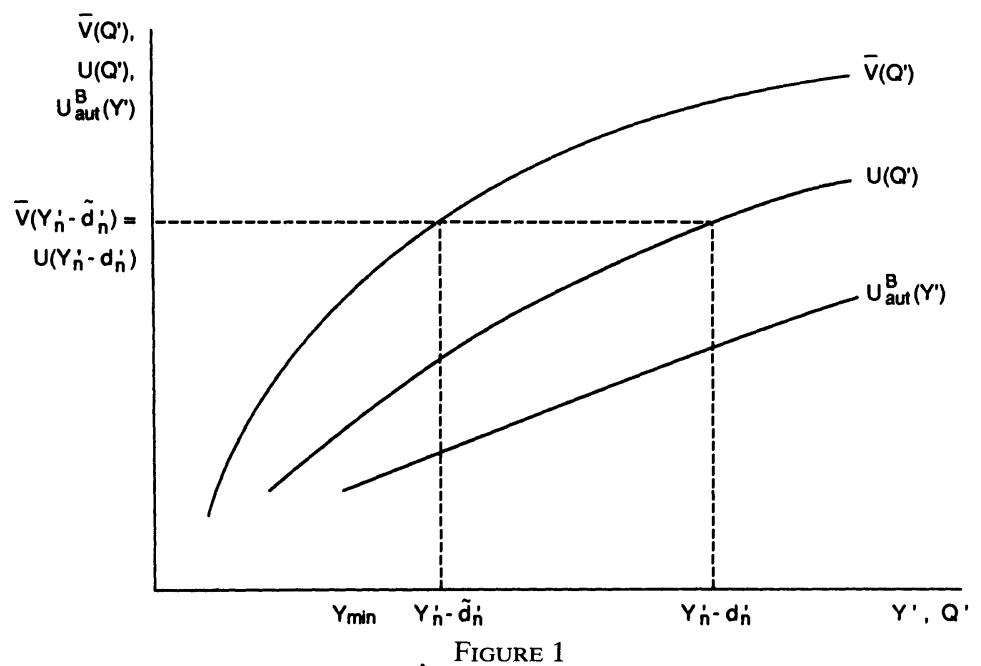

An admissible continuation value function $\hat{U}$ must satisfy two constraints. The first constraint is that $\hat{U}\left(Y^{\prime}-d^{\prime}\left(Y^{\prime}\right)\right) \leqslant \bar{V}\left(Y^{\prime}-d^{\prime}\left(Y^{\prime}\right)\right)$ for all $Y^{\prime}$. The second is that $\hat{U}$ be bounded below by $U_{a u t}^{B}\left(Y_{\min }\right)$. The function $\bar{V}$ is continuous and is not bounded below by $U_{a u t}^{B}\left(Y_{\min }\right)$. Thus, for any admissable pair $(\hat{A}, \hat{U})$, for each realization of output $Y^{\prime}$, we can construct an alternate repayment $\tilde{d}^{\prime}\left(Y^{\prime}\right)$ to solve $\bar{V}\left(Y^{\prime}-\tilde{d}^{\prime}\left(Y^{\prime}\right)\right)=\hat{U}\left(Y^{\prime}-d^{\prime}\left(Y^{\prime}\right)\right)$. If, for some $Y^{\prime}, \hat{U}\left(Y^{\prime}-d^{\prime}\left(Y^{\prime}\right)\right)<\bar{V}\left(Y^{\prime}-d^{\prime}\left(Y^{\prime}\right)\right)$, then $\tilde{d}^{\prime}\left(Y^{\prime}\right)>d^{\prime}\left(Y^{\prime}\right)$.

must imply a contradiction to the hypothesis that $\hat{U}$ is maximal as follows. Since from Lemma $3, I^{*}\left(Q+b, \bar{V}_{\tilde{d}}\right)$ is a continuous function, we may find a $b^{\prime}>b$ and $I^{\prime}=I^{*}\left(Q+b^{\prime}, \bar{V}_{\tilde{d}}\right)$ for which

$$
b^{\prime} \leqslant \delta \sum_{Y^{\prime} \in \boldsymbol{Y}} \tilde{d}^{\prime}\left(Y^{\prime}\right) g\left(Y^{\prime} ; I^{\prime}\right)
$$

and which yields a strictly greater payoff for the borrower. Thus, we have that $\hat{U}$ cannot be the optimal continuation value function unless $\hat{U}=\bar{V}$.

Given the results of Proposition 5, we may rewrite our program characterizing the optimal contract as a functional equation:

\section{Program P*:}

$$
\bar{V}(Q)=\max _{A}(1-\delta) u(c)+\delta \sum_{Y^{\prime} \in \boldsymbol{Y}} \bar{V}\left(Y^{\prime}-d^{\prime}\left(Y^{\prime}\right)\right) g\left(Y^{\prime} ; I\right)
$$

subject to:

$$
\begin{aligned}
& c+I-b \leqslant Q, \quad b,-d^{\prime}\left(Y^{\prime}\right) \leqslant M, \quad c, I \geqslant 0, \\
& b \leqslant \delta \sum_{Y^{\prime} \in \boldsymbol{Y}} d^{\prime}\left(Y^{\prime}\right) g\left(Y^{\prime} ; I\right), \\
& \bar{V}\left(Y^{\prime}-d^{\prime}\left(Y^{\prime}\right)\right) \geqslant U_{a u t}^{B}\left(Y^{\prime}\right) \quad \forall Y^{\prime}, \\
& I \in \underset{I \in[0, Q+b]}{\arg \max }(1-\delta) u(Q+b-\tilde{I})+\delta \sum_{Y^{\prime} \in \boldsymbol{Y}} \bar{V}\left(Y^{\prime}-d^{\prime}\left(Y^{\prime}\right)\right) g\left(Y^{\prime} ; \tilde{I}\right) .
\end{aligned}
$$


This result, that the optimal contract is found as the solution to a functional equation, arises in this environment because it is always possible for the borrower and lenders to trade off a larger current repayment for an improvement of the continuation contract without disrupting the incentive compatibility of the original contract. Because the lenders are short lived, the current lender always strictly prefers a larger current repayment. Thus, the constrained optimal contract which awards all of the surplus to the borrower must have in its continuation constrained optimal contracts (at the new values of the state variable) which award all of the surplus to the borrower. Were we to know the value function $\bar{V}$, the problem of finding the constrained Pareto optimal pattern of capital flows would be a simple static problem. ${ }^{16}$

\section{THE OPTIMAL PATTERN OF CAPITAL FLOWS}

In this section I examine the circumstances under which the optimal pattern of capital flows specifies that the borrower export capital when the lowest levels of output occur. This phenomenon arises as part of the constrained optimal pattern of capital flows when a low realization of output is a sufficiently good indicator in a probabilistic sense that the borrower invested too little. To make these observations about the necessary features of the optimal pattern of capital flows, I employ the following additional two assumptions.

Assumption 6: Assume that the value of repayments at the optimum is increasing in investment:

$$
\sum_{i} d^{\prime}\left(Y_{i}^{\prime}\right)\left(g_{0}\left(Y_{i}^{\prime}\right)-g_{1}\left(Y_{i}^{\prime}\right)\right) \geqslant 0 .
$$

This amounts to an assumption that, at the constrained optimum, the lender would prefer that the borrower make larger rather than smaller investments. ${ }^{17}$

\section{Assumption 7: Assume that the constrained optimal investment level is inte- rior. ${ }^{18}$}

I use these assumptions to construct a Lagrangian for the program (P) above as follows. The assumptions above imply that the optimal incentive compatible

${ }^{16}$ Phelan and Townsend (1991) present numerical methods for computing solutions to recursive formulations of the repeated principal-agent problem. It should be possible to extend their methods to compute solutions to the current problem. The problem here is somewhat more difficult than the repeated principal-agent problem in that the utility possibility correspondence from which continuation values may be drawn is not known beforehand. It must be found together with the optimal contract in an iterative procedure.

${ }^{17}$ In the principal-agent problem, the assumptions that the production technology has the monotone likelihood ratio property and that the agent is risk averse imply that the schedule of payments to the agent is increasing in output and thus at the optimum the expected value of payments to the agent is increasing in effort. (See Rogerson (1985).) This result is critical in establishing the validity of the first order approach to summarizing the incentive constraint. Because I do not know the shape of the value function, $\bar{V}$, I cannot obtain this result directly to justify the first order approach in this problem. Instead, I must assume an analogue of this result to proceed with the first order approach.

${ }^{18}$ Without this assumption, there is no moral hazard problem. 
level of investment $I^{*}$ is the unique solution in $I$ to the first order condition:

$$
\begin{aligned}
& -(1-\delta) u^{\prime}(Q+b-I) \\
& \quad+\delta \lambda^{\prime}(I) \sum_{i} \bar{V}\left(Y_{i}^{\prime}-d^{\prime}\left(Y_{i}^{\prime}\right)\right)\left(g_{0}\left(Y_{i}^{\prime}\right)-g_{1}\left(Y_{i}^{\prime}\right)\right)=0 .
\end{aligned}
$$

By Assumption 6, we may replace this equality constraint by an inequality constraint in our maximization program. Using this relaxed version of constraint $\left(4^{\prime}\right)$, we may write a Lagrangian for the program $(\mathrm{P})$ in terms of controls and compositions of value functions and repayment schedules:

$$
\begin{aligned}
J\left(A, U_{d}, \mu\right)= & (1-\delta) u(c)+\delta \sum_{i} U_{d}\left(Y_{i}^{\prime}\right) g\left(Y_{i}^{\prime} ; I\right) \\
& +\mu_{1}(Q+b-c-I) \\
& +\mu_{2}\left(\delta \sum_{i} d^{\prime}\left(Y_{i}^{\prime}\right) g\left(Y_{i}^{\prime} ; I\right)-b\right) \\
& +\delta \sum_{i} \mu_{3}\left(Y_{i}^{\prime}\right) g\left(Y_{i}^{\prime} ; I\right)\left(U_{d}\left(Y_{i}^{\prime}\right)-U_{a u t}^{B}\left(Y_{i}^{\prime}\right)\right) \\
& +\mu_{4}\left(-(1-\delta) u^{\prime}(Q+b-I)+\delta \sum_{i} U_{d}\left(Y_{\imath}^{\prime}\right) g_{I}\left(Y_{i}^{\prime} ; I\right)\right) \\
& +\delta \sum_{i} \mu_{5}\left(Y_{i}^{\prime}\right) g\left(Y_{i}^{\prime} ; I\right)\left(\bar{V}\left(Y_{i}^{\prime}-d^{\prime}\left(Y_{i}^{\prime}\right)\right)-U_{d}\left(Y_{i}^{\prime}\right)\right) .
\end{aligned}
$$

I analyze the properties of the optimal repayment schedule through an examination of the first order condition of this Lagrangian $J$ with respect to the continuation values $U_{d}\left(Y_{i}^{\prime}\right)$. This first order condition gives conditions under which the no repudiation constraint binds. We then see that the borrower experiences a net capital outflow when this constraint binds.

The first order condition with respect to $U_{d}\left(Y_{i}^{\prime}\right)$ from the Lagrangian $J$ is written:

$$
1+\mu_{4}\left(\frac{g_{I}\left(Y_{i}^{\prime} ; I\right)}{g\left(Y_{i}^{\prime} ; I\right)}\right)=\mu_{5}\left(Y_{i}^{\prime}\right)-\mu_{3} .
$$

Since all the multipliers are nonnegative and $\mu_{4}>0$, then $\mu_{3}>0$ when $1+$ $\mu_{4}\left(g_{I}\left(Y_{i}^{\prime} ; I\right) / g\left(Y_{i}^{\prime} ; I\right)\right)<0$. Thus, the no repudiation constraint binds when $\left(g_{I}\left(Y_{i}^{\prime} ; I\right) / g\left(Y_{i}^{\prime} ; I\right)\right)$ is sufficiently small. By Assumption 5 , this ratio is monotone in $i$, so that if it is sufficiently small, it is so for low realizations of $Y^{\prime}$. This ratio is a measure of the likelihood that a low realization of output is due to low investment as opposed to bad luck. ${ }^{19}$

When the no repudiation constraint on the size of repayments is binding (as indicated by $\left.\mu_{3}>0\right)$, the borrower, in the continuation of the contract, is pushed down to his reservation value. From Proposition 5, $U_{d}\left(Y^{\prime}\right)=$

${ }^{19}$ See Grossman and Hart (1983) and Rogerson (1985) for a discussion of the interpretation of this ratio. 
$\bar{V}\left(Y^{\prime}-d^{\prime}\left(Y^{\prime}\right)\right)$ at the optimum, so that when constraint $\left(3^{\prime}\right)$ binds, $\bar{V}\left(Y^{\prime}-d^{\prime}\left(Y^{\prime}\right)\right)=$ $U_{\text {aut }}^{B}\left(Y^{\prime}\right)$. It is evident from a comparison of the programs that define $\bar{V}$ and $U_{\text {aut }}^{B}$ that when the borrower is driven down to his reservation value, the new loan that the borrower gets after the realization of $Y^{\prime}-d^{\prime}\left(Y^{\prime}\right)$ must be no greater than $d^{\prime}\left(Y^{\prime}\right)$. Thus, when constraint $\left(3^{\prime}\right)$ binds, the borrower experiences a capital outflow.

\section{CONCLUSION}

One of the most striking features of international lending is the repeated occurrence of crises in which creditors demand capital exports from borrowers who have suffered adverse shocks and cause these borrowers to suffer a fall in consumption and investment. The observation that creditors demand repayment and cause the borrower's consumption and investment to fall at the same time that the creditors do not suffer a similar economic setback is inconsistent with the basic prediction of the complete markets model that there should be risk sharing in the international lending relationship. In this paper, I put forward a model of international lending which specified moral hazard and the risk of repudiation as the two reasons why risk sharing between creditors and debtors is incomplete. Then I showed that a debt crisis-like phenomenon is part of the model's constrained optimal allocation. Specifically, I examined the constrained optimal pattern of capital flows between lenders who cannot observe whether the borrower invests or consumes the proceeds of loans and a borrower who can repudiate his debts. These features of the problem analyzed here are intended to capture the difficulties actual lenders have both in evaluating the efficiency of a sovereign borrower's investments and in enforcing the repayment of debt across national boundaries. I showed that the constrained optimal pattern of capital flows over an infinite horizon necessarily has a simple Markov structure. I then showed that the optimal contract has the property that, for incentive reasons, the borrower experiences a capital outflow and a fall in consumption and investment when a range of the lowest realizations of output in the borrowing country occurs. This last feature of the model is the feature which is analogous to the debt crises which we observe.

Department of Economics, University of Chicago, 1126 East 59th Street, Chicago, IL 60637, U.S.A.

Manuscript received July, 1988; final revision received March, 1990.

\section{APPENDIX}

Proof of Proposition 1: I proceed by constructing for each $w_{Q} \in B(W)(Q)$ for some $Q$ an allocation $\sigma\left(w_{Q}\right)$ such that $U^{B}\left(\sigma\left(w_{Q}\right)\right)=w_{Q}$ and such that $\sigma\left(w_{Q}\right)$ satisfies constraints (1)-(4). I present the proof in three steps. In the first step I construct $\sigma\left(w_{Q}\right)$. In the second step I verify that $U^{B}\left(\sigma\left(w_{Q}\right)\right)=w_{Q}$. In the third step I verify that $\sigma\left(w_{Q}\right)$ satisfies constraints (1)-(4). 
Step 1: Choose a $w_{Q^{0}} \in B(W)\left(Q_{0}\right)$ for some $Q_{0}$. There is an admissible pair $\left(A\left(w_{Q^{0}}\right), U\left(w_{Q^{0}}\right)\right)$ corresponding to $w_{Q^{0}}$ such that $E\left(A\left(w_{Q^{0}}\right), U\left(w_{Q^{0}}\right)\right)(Q)=w_{Q^{0}}$. Define $\sigma\left(w_{Q^{0}}\right)$ inductively as follows: Let $\sigma_{0}\left(w_{Q^{0}}\right)=A\left(w_{Q^{0}}\right)$. For any realization of $Y_{1}$ and new value for the state $Q_{1}=Y_{1}-d_{1}\left(Y_{1}\right)$, $Q^{1}=\left(Q_{0}, Q_{1}\right)$, define $w_{Q^{1}}=U\left(w_{Q^{0}}\right)\left(Q_{1}\right)$. By the admissibility of $\left(A\left(w_{Q^{0}}\right), U\left(w_{Q^{0}}\right)\right)$ and $W$ self-generating, $w_{Q^{1}} \in W\left(Q_{1}\right) \subseteq B(W)\left(Q_{1}\right)$ so that there is an admissible pair $\left(A\left(w_{Q^{1}}\right), U\left(w_{Q^{1}}\right)\right)$ corresponding to $w_{Q^{1}}$ such that $E\left(A\left(w_{Q^{1}}\right), U\left(w_{Q^{1}}\right)\right)(Q)=w_{Q^{1}}$. Let $\sigma_{1}\left(w_{Q^{0}}\right)\left(Q^{1}\right)=A\left(w_{Q^{1}}\right)$. Repeat this procedure to define all of $\sigma\left(w_{Q^{0}}\right)$.

Step 2: Now I show for any $w_{Q^{0}} \in W\left(Q_{0}\right)$ for some $Q_{0}$, that $U^{B}\left(\sigma\left(w_{Q^{0}}\right)\right)=w_{Q^{0}}$. We have by the fact that $w_{Q^{0}}=E\left(A\left(w_{Q^{0}}\right), U\left(w_{Q^{0}}\right)\right)(Q)$ :

$$
w_{Q^{0}}=(1-\delta) u(c)+\delta \sum_{Y_{t} \in \boldsymbol{Y}} U\left(w_{Q^{0}}\right)\left(Y_{1}-d_{1}\left(Y_{1}\right)\right) g\left(Y_{1} ; I\right)
$$

(where $Q_{1}=Y_{1}-d_{1}\left(Y_{1}\right)$ ). Since $\left.\sigma\left(w_{Q^{0}}\right)\right|_{Q^{1}}=\sigma\left(w_{Q^{1}}\right)$, we have

$$
U^{B}\left(\sigma\left(w_{Q^{0}}\right)\right)=(1-\delta) u(c)+\delta \sum_{Y_{1} \in \boldsymbol{Y}} U^{B}\left(\sigma\left(w_{Q^{1}}\right)\right) g\left(Y_{1} ; I\right)
$$

where $w_{Q^{1}}=U\left(w_{Q^{0}}\right)\left(Q_{1}\right)$. Subtraction gives

$$
w_{Q^{0}}-U^{B}\left(\sigma\left(w_{Q^{0}}\right)\right)=\delta\left(\sum_{Y_{1} \in Y} w_{Q^{1}}-U^{B}\left(\sigma\left(w_{Q^{1}}\right)\right) g\left(Y_{1} ; I\right)\right) .
$$

Since $g$ is a probability distribution, we have that

$$
\left|w_{Q^{0}}-U^{B}\left(\sigma\left(w_{Q^{0}}\right)\right)\right| \leqslant \delta \sup _{w_{Q^{1}} \in B(W)\left(Q_{1}\right)}\left|w_{Q^{1}}-U^{B}\left(\sigma\left(w_{Q^{1}}\right)\right)\right| .
$$

Since this holds for all $w_{Q^{0}}$ we have that

$$
\sup _{w_{Q^{0}} \in B(W)\left(Q_{0}\right)}\left|w_{Q^{0}}-U^{B}\left(\sigma\left(w_{Q^{0}}\right)\right)\right| \leqslant \delta \sup _{w_{Q^{1}} \in B(W)\left(Q_{1}\right)}\left|w_{Q^{1}}-U^{B}\left(\sigma\left(w_{Q^{1}}\right)\right)\right| .
$$

Since $\delta<1$ and each set $B(W)(Q)$ is uniformly bounded given the uniform bound on $W(Q)$ and the bound on $u$, we have

$$
w_{Q}=U^{B}\left(\sigma\left(w_{Q}\right)\right) \quad \forall w_{Q} \in B(W)(Q) \text { for some } Q .
$$

Step 3: Here I verify that $\sigma\left(w_{Q}\right)$ satisfies conditions (1)-(4) of admissibility. The allocation $\sigma\left(w_{Q}\right)$ satisfies one round versions of the constraints (1)-(4) by definition. That $q\left(w_{Q}\right)$ satisfies constraints (1)-(3) is immediate. We need to verify that the borrower, when faced with the lending program specified by $\sigma\left(w_{Q}\right)$, does not have a payoff improving multi-round (or potentially infinite-round) deviation from the investment program. We show that there are no finite round deviations from $\sigma\left(w_{Q^{0}}\right)$ for the borrower that would be payoff improving by induction as follows. There are no round zero deviations $\sigma\left(w_{Q^{0}}\right)$ that are payoff improving for the borrower by definition. Assume that for all $Q^{0}, w_{Q^{0}}$, there are no payoff improving deviations for the borrower from $\sigma\left(w_{Q^{0}}\right)$ in the initial $t$ periods. After any realization of $Q^{1}$, by the construction of $\sigma\left(w_{Q^{0}}\right)$ and the inductive hypothesis, the continuation allocation $\left.\sigma\left(w_{Q^{0}}\right)\right|_{Q^{1}}=\sigma\left(w_{Q^{1}}\right)$ also has the property that there are no payoff improving deviations for the borrower in the first $t$ periods. Thus there are no payoff improving deviations from $\sigma\left(w_{Q^{0}}\right)$ for the borrower in the initial $t+1$ rounds of play. We know that there are no infinite-round deviations from $\sigma\left(w_{Q^{0}}\right)$ that are payoff improving for the borrower by the continuity of the borrower's preferences. Since the set of feasible payoffs for the borrower is bounded, the maximum gain to the borrower from deviations in the tail is bounded and must go to zero when discounted.

Proof of Proposition 2: We show that the borrower's utility possibility correspondence $V$ is self-generating, which, by Proposition 1, gives us the result that $V=B(V)$. Let $v_{Q} \in V(Q)$ be a 
payoff generated by the allocation $\sigma\left(v_{Q}\right)$ which we assume satisfies constraints (1)-(4). Define $\left(A\left(v_{Q}\right), U\left(v_{Q}\right)\right)$ as follows: Let

$$
A\left(v_{Q}\right)=\sigma_{0}\left(v_{Q}\right) \text { and } U\left(v_{Q}\right)\left(Q_{1}\right)=U^{B}\left(\left.\sigma\left(v_{Q}\right)\right|_{Q^{1}}\right) .
$$

$E\left(A\left(v_{Q}\right), U\left(v_{Q}\right)\right)(Q)=v_{Q}$. Since $\sigma\left(v_{Q}\right)$ satisfies the original versions of constraints (1)-(4), $\left(A\left(v_{Q}\right), U\left(v_{Q}\right)\right)$ clearly satisfy the one-round versions and are thus admissible.

\section{REFERENCES}

Abreu, D., D. Pearce, and E. Stacchetti (1986): "Optimal Cartel Equilibria with Imperfect Monitoring," Journal of Economic Theory, 39, 251-269.

- (1990): "Toward a Theory of Discounted Repeated Games with Imperfect Monitoring," Econometrica, 58, 1041-1063.

Bulow, J., AND K. Rogoff (1989): “A Constant Recontracting Model of Sovereign Debt,” Journal of Political Economy, 97, 155-178.

- (1989): "Sovereign Debt: Is to Forgive to Forget?," American Economic Review, 79, 43-50.

Eichengreen, B., AND R. Portes (1986): "Debt and Default in the 1930's: Clauses and Consequences," European Economic Review, 30, 599-640.

FudenberG, D., B. Holmstrom, ANd P. Milgrom (1990): "Short-Term Contracts and Long-Term Agency Relationships," Journal of Economic Theory, 52, 194-206.

Grossman, H., and J. van Huyck (1988): "Sovereign Debt as a Contingent Claim: Excusable Default, Repudiation, and Reputation," American Economic Review, 78, 1088-1097.

Grossman, S. J., and O. D. Hart (1983): "An Analysis of the Principal-Agent Problem," Econometrica, 51, 7-45.

Lindert, P. H., AND P. J. Morton (1989): "How Sovereign Debt Has Worked," in Developing Country Debt and Economic Performance: The International Financial System, ed. by Jeffery D. Sachs. Chicago: University of Chicago Press for the NBER.

Phelan, C., AND R. M. TownsEnd (1991): "Computing the Optimal Insurance-Incentive Tradeoff for Multiperiod, Information Constrained Economies," Review of Economic Studies, forthcoming.

Rogerson, W. P. (1985): "The First Order Approach to Principal-Agent Problems," Econometrica, $53,1357-1367$.

Spear, S. E., AND S. SRIVAStava (1987): “On Repeated Moral Hazard with Discounting,” Review of Economic Studies, 55, 599-617. 